\title{
Prevalence of motor problems in children with attention deficit hyperactivity disorder in Hong Kong
}

\author{
KW Tsui *, Kelly YC Lai, Marshall MC Lee, Caroline KS Shea, Luke CT Tong
}

\section{A B S T R A C T}

Introduction: Local data on the occurrence of motor problems in children with attention deficit hyperactivity disorder are not available but an understanding of this important issue may enable better planning of medical services. We aimed to determine the prevalence of motor problems in children with attention deficit hyperactivity disorder in a local population.

Methods: In this descriptive cross-sectional study, children aged 6 to 9 years diagnosed with attention deficit hyperactivity disorder over a period of 6 months from 1 July to 31 December 2011 were recruited from the Joint Paediatric and Child Psychiatric ADHD Program in New Territories East Cluster in Hong Kong. Movement Assessment Battery for Children and Developmental Coordination Disorder Questionnaire-Chinese version were used to determine the presence of motor problems.

Results: Data from 95 participants were included in the final analysis. The number of children who had no, borderline, or definite motor problems was

This article was published on $11 \mathrm{Mar}$ 2016 at www.hkmj.org. 63,15 , and 17 , respectively. It is estimated that up to one third of local children with attention deficit hyperactivity disorder might have developmental coordination disorder.

Conclusions: Motor problems are common in local children with attention deficit hyperactivity disorder and figures are comparable with those from other parts of the world. Despite the various limitations of this study, the magnitude of the problem should not be overlooked.

Hong Kong Med J 2016;22:98-105

DOI: 10.12809/hkmj154591

${ }^{1}$ KW Tsui *, MB, BS, FHKCPaed

${ }^{2}$ KYC Lai, MB, BS, FHKAM (Psychiatry)

${ }^{3}$ MMC Lee, FHKCPsy

${ }^{3}$ CKS Shea, FHKCPsy

${ }^{1}$ LCT Tong, FHKCPaed, FHKAM (Paediatrics)

Department of Paediatrics and Adolescent Medicine, Alice Ho Miu Ling Nethersole Hospital, Tai Po, Hong Kong

2 Department of Psychiatry, The Chinese University of Hong Kong, Shatin, Hong Kong

${ }^{3}$ Department of Psychiatry, Alice Ho Miu Ling Nethersole Hospital, Tai Po, Hong Kong

* Corresponding author: tsuikw@ha.org.hk

An earlier version of this paper was presented at the Combined PN and DBP Joint Scientific Meeting, organised by the Hong Kong Society of Child Neurology and Developmental Paediatrics held in Hong Kong on 27 March 2014

New knowledge added by this study

- This study determined the prevalence of motor problems in local children with attention deficit hyperactivity disorder (ADHD), which was not previously available in Hong Kong.

Implications for clinical practice or policy

It is important to include motor performance as part of the assessment and management of children with ADHD.

\section{Introduction}

Attention deficit hyperactivity disorder (ADHD) is one of the most common neurodevelopmental problems in children. In Hong Kong, the prevalence of ADHD among primary one Chinese schoolboys has been reported to be $8.9 \%{ }^{1}$ Associated neurodevelopmental co-morbidities and mental health problems are frequently found among individuals with ADHD. The majority $(67 \%)$ have at least one co-morbidity and the degree of functional impairment increases stepwise with the number of associated co-morbidities that includes dyslexia, other specific learning disorders, motor incoordination, anxiety, depression, oppositional defiance disorder, tics, and Tourette syndrome..$^{2,3} \mathrm{~A}$ diverse group of motor problems has been found to be co-morbid with ADHD, including an increase in associated movements. ${ }^{4}$ Individual subtests of the Motor Function Neurological Assessment reveal that $80 \%$ to $96 \%$ of children with ADHD, compared with $0 \%$ to $44 \%$ of a control group, demonstrate moderateto-severe problems in motor inhibition and proximal truncal stabilisation. ${ }^{5}$ Children with ADHD also experience greater difficulties in handwriting and 
penmanship, which is independent of other motor problems associated with the disorder., ${ }^{6,7}$

Developmental coordination disorder (DCD) is a well-recognised motor disability in an otherwise healthy individual. The Diagnostic and Statistical Manual of Mental Disorders, 5th edition (DSM-5) defines DCD as marked impairment in performance of motor skills, significantly interfering with daily activities and/or academic achievements. ${ }^{8}$ The degree of coordination deficit is not consistent with the child's intellectual ability and is not caused by pervasive developmental disorder or general medical condition. The prevalence of DCD in the normal population varies from $4 \%$ to $19 \%{ }^{9-12}$ Clinically, DCD is a heterogeneous condition with coordination deficits involving gross motor skills, fine motor skills, or both. Affected children show difficulties and restricted participation in daily living, eg self-care activities, academic achievement, leisure, and sports. Internalising symptoms and motor coordinating problems frequently co-occur in these children but their causal relationship is unclear. ${ }^{13}$ This condition is believed to be lifelong and the majority of affected children will not outgrow the problems. They will continue to experience motor difficulties, poor selfconcept, and various kinds of problems at school. ${ }^{14}$ Children with DCD benefit from accommodation in school and multidisciplinary interventions that focus on task-specific training activities relevant to daily living and function. ${ }^{15-17}$

The prevalence of DCD in children with ADHD has been reported to be as high as $30 \%$ to $50 \%$, depending on case definitions. ${ }^{18,19}$ The presence of ADHD co-morbid with DCD carries the worst prognosis and predicts poor psychosocial function in early adulthood. ${ }^{20}$ Therefore early identification and intervention in DCD is important in this group of children who are already adversely affected by ADHD.

Local data on the occurrence of motor problems in children with ADHD are not available but an understanding of this important issue may enable better planning of medical services. As such, the aim of this study was to estimate the prevalence of motor problems in a sample of children with ADHD at a public hospital in Hong Kong.

\section{Methods}

The participants were selected from patients referred to the Joint Paediatric and Child Psychiatric ADHD Program, a collaboration of Paediatricians and Child Psychiatrists of the New Territories East Cluster (NTEC) of Hong Kong over a period of 6 months from 1 July to 31 December 2011. The hospitals in NTEC serve a population of approximately one million and this ADHD Program is the only public service provided for children with ADHD within the cluster. Hospital records of patients aged 6 to 9 years at their

\section{專注力失調及過度活躍症（即多動症）香港小兒 患者中有動作協調障礙的比率$$
\text { 徐夙環、黎以菁、李明沖、佘嘉倩、唐志德 }
$$

引言：香港缺乏有關多動症兒童患者的動作協調障礙數據。值得留意 的是, 這些數據可以讓我們更好地規劃本地的醫療服務。本研究旨在 找出香港多動症小兒患者中有動作協調障礙的比率。

方法：在這個描述性橫斷面研究中, 我們於2011年7月1日至 12 月 31 日期間從香港新界東醫院聯網的聯合兒科和兒童精神科多動症計劃中 招募了6 歲至9歲被診斷出患有多動症的兒童。使用兒童動作評量量 表 (Movement Assessment Battery for Children-Chinese version) 和動作協調問卷中文版（Developmental Coordination Disorder Questionnaire）來決定他們是否有動作協調障礙。

結果：最終分析了95名參與者的資料。當中有 63 人沒有動作協調障 礙、 15 人有疑似動作協調障礙, 另 17 人被確診為有動作協調障礙。據 估計，本地多動症兒童中有高達三分之一有動作協調障礙

結論：香港的多動症兒童患者中同時有動作協調障礙的情況很普遍, 比率與其他地區相近。雖然本研究有不足的地方, 這個問題的重要性 不容忽視。

first visit were reviewed. Potential candidates were those with a diagnosis of ADHD clearly documented in their record and in whom medication for ADHD was indicated. This study also included children with confirmed ADHD but whose parents had declined drug treatment. The diagnosis of ADHD was based on DSM-IV through clinical judgement of individual physicians during the clinic visit. Rating scales, such as Strengths and Weaknesses of ADHD symptoms and Normal Behavior Scale, were used in some patients as a reference but the diagnosis of ADHD remained clinical in our daily practice. In order to recruit patients with a more definitive diagnosis of ADHD, only those in whom drug treatment was indicated were included as potential candidates. This sample should therefore represent most children diagnosed with ADHD in a clinic setting. Patients were excluded when hospital records documented the presence of intellectual disability, features of autistic spectrum disorder, or medical conditions that could affect motor performance, such as cerebral palsy, hemiplegia, or a neuromuscular condition. This was consistent with the exclusion criteria for DCD in DSM-IV.

Movement Assessment Battery for Children (MABC) is commonly used as a standardised tool to diagnose DCD in both clinical and research settings. ${ }^{21}$ It provides an objective and quantitative measure of the motor performance of children between 4 and 12 years of age. There is good concurrent validity between MABC and BruininksOseretsky test ${ }^{22}$ and a local study has also shown that 
this instrument provides satisfactory inter-rater and test-retest reliability. ${ }^{23}$ The assessment comprises eight test items related to three motor domains, namely manual dexterity, ball skills, and balance (static and dynamic). The sum of scores from the eight test items generates a total impairment score (TIS) and categorises children into one of the three groups-no, borderline, or definite motor problems. The Developmental Coordination Disorder Questionnaire (DCDQ) is a parent-reporting questionnaire first developed in Canada as a reliable and valid screening tool for DCD. ${ }^{24,25}$ It comprises statements by which parents rate their child's motor performance in comparison with other children of the same age for ball games, balance, and handwriting skills across home, school, and play environments. A Chinese version of the DCDQ (DCDQ-C) has been validated in Taiwan as a screening tool for DCD in a Chinese-speaking community. ${ }^{26}$ Parents responded to each of the 15 questions on a 5 -point Likert scale to generate a total raw score which was then converted into a probability of having DCD A score of $>40 \%$ chance is suggestive of DCD while $25 \%$ to $40 \%$ chance indicates a suspected case. In this study, DSM-IV was used to diagnose DCD and the questionnaire provided information on one of the diagnostic criteria about any impairment in daily functions related to motor performance.

The selected candidates were invited to attend a one-to-one study session that lasted approximately 30 minutes. The investigator performed MABC on the children after obtaining consent from the parents/carers. Baseline information was also collected and included age, gender, primary school level, ADHD medication use, drugs taken before assessment, gestational age, birth weight, and socioeconomic group.

Statistical analysis was performed using the Statistical Package for the Social Sciences (Windows version 16.0; SPSS Inc, Chicago [IL], US). The result of MABC was used as the diagnostic standard for calculation of DCD prevalence in children with ADHD. A diagnosis of DCD was made when the TIS was $\geq 10$, indicating 'borderline' (TIS $=10$ to 13.5) or 'definite' (TIS >13.5) motor problems, and representing the 15 th or 5 th percentile of TIS in a general population, respectively. The cut-off at either the 5 th or 15 th percentile varied among published data. As diagnosis of DCD requires fulfilling other criteria, such as impairment of daily activities, raising the cut-off to the 15 th percentile in MABC could improve the sensitivity of the test. Nonetheless, use of the DCDQ-C avoided the risk of overdiagnosis. Prevalence was expressed as the percentage of DCD cases in participants with ADHD who underwent MABC assessment. The Chi squared test was applied to detect any difference in characteristics of participants with and without DCD. Analysis of variance was used to detect any significant difference in TIS of the MABC between DCDQ-C-defined motor performance groups. The concurrent validity was investigated by testing the probability score of DCDQ-C against TIS of MABC with Pearson's correlation coefficient. Sensitivity, specificity, and positive and negative predictive values of DCDQ-C were calculated.

Ethical approval was obtained from the Joint Chinese University of Hong Kong and NTEC Clinical Research Ethics Committee.

\section{Results}

From 1 July to 31 December 2011, 304 new cases were referred to the Joint Paediatric and Child Psychiatric ADHD Program of NTEC. Of the 195 potential candidates aged 6 to 9 years, diagnosis of ADHD was unconfirmed in 38. After exclusion of 21 patients with autistic features, one patient with moderate intellectual disability, one patient with left hemiplegia, and one patient with possible neurological deficit following cardiopulmonary resuscitation, 133 children were eligible for this study. Of the 132 parents who were successfully contacted, 107 agreed to participate. The MABC was tested on 102 candidates and five defaulted. The results of seven participants were rejected as they were uncooperative, making MABC scoring unreliable. Of the 133 eligible candidates, statistical analysis was performed on results from 95 (71.4\%), with 63 males and 32 females and a mean age of 7.8 years. The Figure summarises the workflow of this study and the candidate recruitment process.

Table 1 shows the results of MABC performed on the 95 participants. Based on the TIS, three motor performance groups were identified: no motor problem $(n=63$; mean TIS $=4.75$ with $95 \%$ confidence interval [CI] of 4.1-5.4), borderline motor problem $(n=15$; mean TIS $=11.53$ with $95 \%$ CI of 11.0-12.1), and definite motor problem $(n=17$; mean TIS $=18.53$ with $95 \%$ CI of 16.6-20.5). Using the 15 th percentile of motor performance in MABC as a cut-off, the prevalence of motor problems in this group of children with ADHD was 33.7\% (95\% CI, $24.2 \%-43.2 \%)$.

Table 2 shows the baseline information about the two groups with motor problems (borderline and definite) and the group with no motor problems and includes sex, perinatal history, socio-economic background, drug treatment, and previous motor training. There was no statistical difference between these two groups, except for a history of receiving motor training at a younger age $(\mathrm{P}=0.002)$.

Two carers who accompanied a child to the study session could not read Chinese, therefore 93 completed DCDQ-C were analysed. The questionnaire identified 71 and 22 participants with 


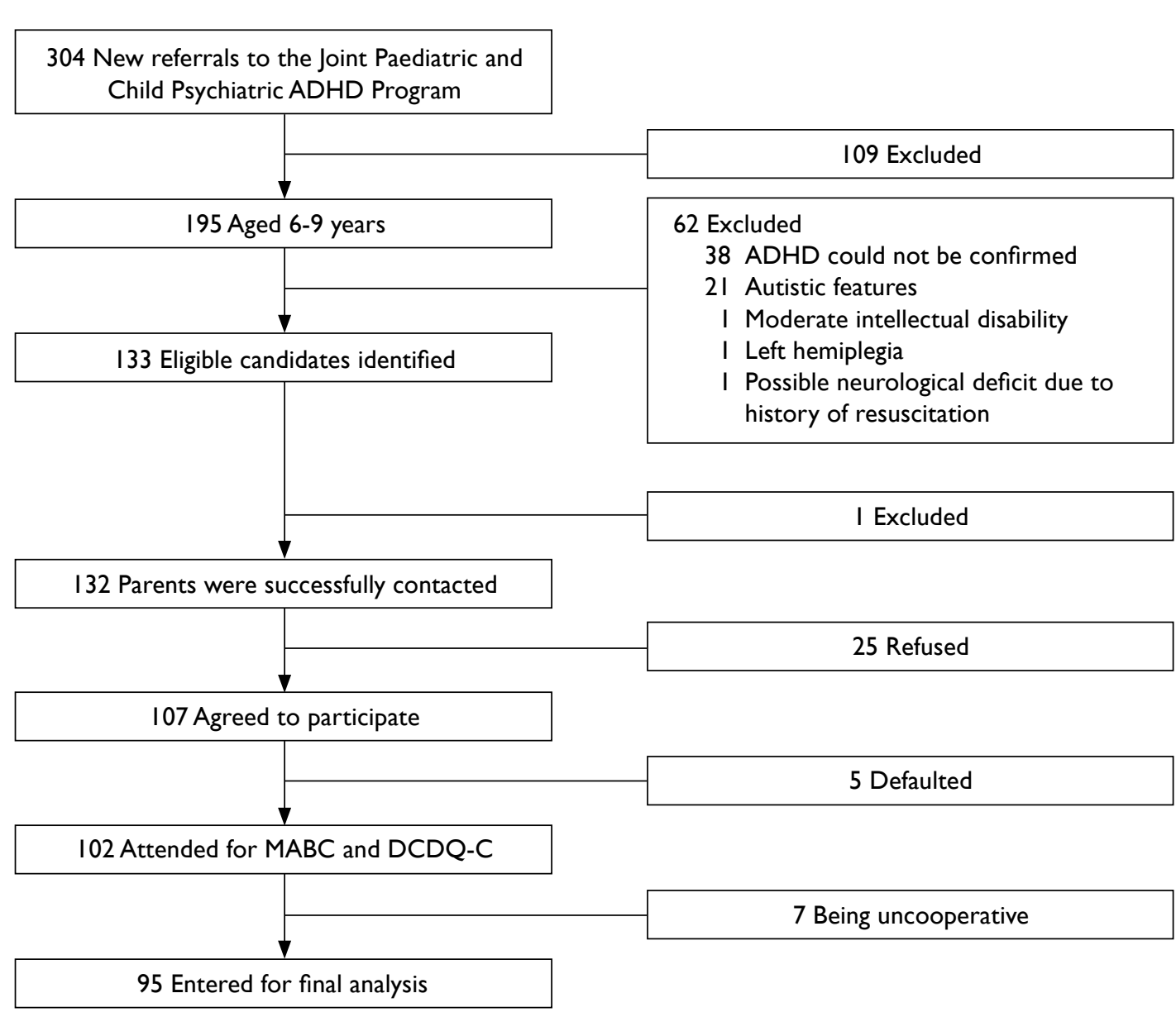

FIG. Workflow of the study and recruitment of participants

Abbreviations: $\mathrm{ADHD}=$ attention deficit hyperactivity disorder; $\mathrm{DCDQ}-\mathrm{C}=$ Chinese version of the Developmental Coordination Disorder Questionnaire; MABC = Movement Assessment Battery for Children

TABLE I. Results of MABC comparing mean and standard deviation of TIS among the three motor performance groups

\begin{tabular}{lccc}
\hline Motor performance group & No. of participants & Mean TIS & Standard deviation \\
\hline No motor problem & $63(66.3 \%)$ & 4.75 & 2.51 \\
Borderline motor problem & $15(15.8 \%)$ & 11.53 & 1.01 \\
Definite motor problem & $17(17.9 \%)$ & 18.53 & 3.77 \\
\hline
\end{tabular}

Abbreviations: $\mathrm{MABC}=$ Movement Assessment Battery for Children;TIS = total impairment score

no motor problems and suspected motor problems, specificity of DCDQ-C on identification of DCD respectively, but none was found to have definite was $37.5 \%$ and $83.6 \%$, respectively. The positive DCD ( $>40 \%$ chance) [Table 3]. For correlation predictive value of DCDQ-C was $54.5 \%$ and the between MABC and DCDQ-C, the Kappa value was negative predictive value was $71.8 \%$. Thus DCDQ-C 0.228 indicating a low agreement between the two could quite reliably exclude DCD but was rather instruments $(\mathrm{P}=0.023)$. Using $\mathrm{MABC}$ as a standard insensitive when identifying motor problems in measure for motor performance, sensitivity and children with ADHD in Hong Kong. 
TABLE 2. Comparison of sex, and perinatal, social and treatment characteristics of participants with and without motor problems*

\begin{tabular}{|c|c|c|c|}
\hline Characteristic & No motor problem $(n=63)$ & With motor problems $(n=32) \dagger$ & $P$ value \\
\hline \multicolumn{4}{|l|}{ Sex } \\
\hline Male & $48(76.2 \%)$ & $22(68.8 \%)$ & 0.44 \\
\hline Female & $15(23.8 \%)$ & $10(31.3 \%)$ & \\
\hline \multicolumn{4}{|l|}{ Prematurity (weeks) } \\
\hline Full-term (>37) & 58 (96.7\%) & $28(87.5 \%)$ & $0.18 \S$ \\
\hline $34-37$ & $2(3.3 \%)$ & $4(12.5 \%)$ & \\
\hline$<34$ & 0 & 0 & \\
\hline \multicolumn{4}{|l|}{ Birth weight (g) } \\
\hline$\geq 2500$ & $56(91.8 \%)$ & $27(84.4 \%)$ & 0.42 \\
\hline $2000-2499$ & $4(6.6 \%)$ & $3(9.4 \%)$ & \\
\hline 1500-1999 & $1(1.6 \%)$ & $2(6.3 \%)$ & \\
\hline$<1500$ & 0 & 0 & \\
\hline \multicolumn{4}{|l|}{ Socio-economic groups } \\
\hline I - professional / managerial & $6(9.7 \%)$ & $6(19.4 \%)$ & 0.72 \\
\hline II - clerical & 21 (33.9\%) & $8(25.8 \%)$ & \\
\hline III - services / sales & $10(16.1 \%)$ & $5(16.1 \%)$ & \\
\hline IV - skilled labours & $22(35.5 \%)$ & $10(32.2 \%)$ & \\
\hline V-unskilled / home duties & $3(4.8 \%)$ & $2(6.5 \%)$ & \\
\hline \multicolumn{4}{|l|}{ Private housing } \\
\hline Yes & $40(64.5 \%)$ & $23(71.9 \%)$ & 0.47 \\
\hline No & 22 (35.5\%) & $9(28.1 \%)$ & \\
\hline \multicolumn{4}{|l|}{ On medication } \\
\hline Yes & $48(76.2 \%)$ & $21(65.6 \%)$ & 0.28 \\
\hline No (never medicated) & $15(23.8 \%)$ & $11(34.4 \%)$ & \\
\hline \multicolumn{4}{|l|}{ Assessment under drug effect } \\
\hline Yes & $20(31.7 \%)$ & $6(18.8 \%)$ & 0.18 \\
\hline No & $43(68.3 \%)$ & $26(81.3 \%)$ & \\
\hline \multicolumn{4}{|l|}{ Previous motor training } \\
\hline Yes & $4(6.7 \%)$ & $11(34.4 \%)$ & $0.002 \S$ \\
\hline No & 56 (93.3\%) & 21 (65.6\%) & \\
\hline
\end{tabular}

* Percentages were based on the number of participants with the information available for analysis

$\uparrow$ Because of rounding, not all percentages total 100

‡ P values were calculated by Chi squared test

$\S$ Fisher's exact test

\section{Discussion}

In this clinic sample of children with ADHD, the results of MABC revealed that $15.8 \%$ had borderline and $17.9 \%$ had definite motor problems. Overseas studies have often used the 15th percentile of TIS in MABC as the cut-off for identification of DCD. ${ }^{17,19,25}$ By using the same standard here, participants who belonged to the borderline and definite motor problem groups could be potentially diagnosed as having DCD. A diagnosis of DCD, however, requires confirmation of motor problems and impaired daily functions. Initially, DCDQ-C was intended to provide the impairment criteria for a DCD diagnosis but it could not be reliably applied here due to the significant lack of agreement with MABC in this study sample. We therefore estimated that DCD may occur in up to one third of patients with ADHD, a figure that is comparable with the literature.

In our clinical experience, motor difficulties are usually not a common presenting symptom during a medical consultation for ADHD. There are a few possible reasons why motor performance may 
be overlooked. First, the parents of these children are often overwhelmed by the symptoms of ADHD and attribute all difficulties to a single diagnosis. In addition, it may be difficult for parents to differentiate symptoms related to motor impairment from those related to ADHD, for examples, bumping into objects, poor postural stability, and illegible handwriting. Second, cultural influences may play a part. Hong Kong children adopt a very sedentary lifestyle and are probably the most physically inactive students in the world. ${ }^{27}$ Sports skills are not essential for most local children in the school and social environment. Third, there was less diversity for participation in leisure activities among ADHD children compared with their normal peers. ${ }^{28}$ Children with ADHD were encouraged to participate in tutorial lessons to support academic achievement, rather than other non-academic-related activities. They spent many hours after school every day for completion of homework and revision, leaving little time for sports or other leisure activities. Limited participation in physical activities masks underlying motor problems and conversely means any motor talent goes unrecognised. Therefore, clinicians who manage children with ADHD should be aware of these issues and need to consider motor problems (or DCD) as a factor that causes persistent impairment, especially when the symptoms of ADHD improve.

The prevalence of DCD in children born extremely premature $(<29$ weeks $)$ or with extremely low birth weight $(<1000 \mathrm{~g})$ has been reported to be high, which was around $42 \%$ in one study. ${ }^{29} \mathrm{~A}$ recent meta-analysis of studies in school-aged children with very low birth weight (VLBW)/very preterm reported an odds ratio (OR) of up to $8.66 .^{30}$ In our study, $6.5 \%$ and $10.8 \%$ of children had a history of prematurity or low birth weight, respectively, but none was born very preterm or with VLBW. It was therefore not surprising to see no significant difference between the groups with and without motor problems in terms of maturity and birth weight. Local figures published in 1998 show that the incidence of very preterm delivery $(<34$ weeks) and very/extremely low birth weight $(<1500 \mathrm{~g})$ was $2.22 \%$ and $1.25 \%$, respectively. ${ }^{31}$ The sample size of the current study was simply not large enough to include these children.

There are studies that show improved motor performance and quality of life in children with comorbid ADHD and DCD following treatment with methylphenidate. ${ }^{32-34}$ As shown in Table 2, a lower prevalence of motor problems was found in children who were prescribed regular medication or who had taken medication prior to the assessment $(\mathrm{OR}=0.6$ and 0.5 , respectively) but this was not statistically significant $(\mathrm{P}=0.28$ and 0.18 , respectively). This may be because we recruited some children who had been recently diagnosed with ADHD and medication was
TABLE 3. Results of DCDQ-C and its agreement with MABC*

\begin{tabular}{lccccc}
\hline DCDQ-C results & \multicolumn{2}{c}{ MABC results } & & \multicolumn{2}{c}{ TIS results } \\
\cline { 2 - 3 } \cline { 5 - 6 } & No DCD & DCD & & Mean & Standard deviation \\
\hline Normal $(n=71)$ & 51 & 20 & & 8.01 & 6.02 \\
Suspected DCD $(n=22)$ & 10 & 12 & & 9.80 & 5.64 \\
DCD $(n=0)$ & 0 & 0 & & - & - \\
Total & $\mathbf{6 1}$ & $\mathbf{3 2}$ & & - & - \\
\hline
\end{tabular}

Abbreviations: DCD = developmental coordination disorder; DCDQ-C = Chinese version of the Developmental Coordination Disorder Questionnaire; MABC = Movement Assessment Battery for Children; TIS = total impairment score

* Sensitivity and specificity of DCDQ-C in detection of DCD was $37.5 \%$ and $83.6 \%$, respectively; Kappa value $=0.228$

+ Analysis of variance on TIS between DCDQ-C-defined normal and suspected DCD groups $(P=0.22)$

not yet optimised at the time of MABC testing, or simply because of a lack of statistical power due to the small number of subjects. To better understand this issue, further studies should be carried out to specifically examine the effect of ADHD medication on motor performance.

Of the 15 participants who had received previous motor training, 11 had motor problems. This group was quite heterogeneous and, interestingly, many parents could not recall the exact reason for the motor training. As mentioned before, DCD is a relatively stable condition and intervention should focus on specific motor skills. Previous training does not preclude children from having future motor problems as demand for activities, such as handwriting and participation in sports, increases when children progress from preschool to primary school. It is therefore vital to determine whether motor skills are at an age-appropriate level for both academic and extracurricular activities and provide task-specific training whenever indicated.

Although the DCDQ-C has been validated for use in Taiwan, which is a Chinese community similar to Hong Kong, the questionnaire was not appropriate for local Hong Kong children. This demonstrates the need to be cautious when adopting an assessment tool from overseas without local validation, even from an area with comparable cultural and socio-economic background. Furthermore, a questionnaire cannot replace detailed history taking in clinical practice that is indispensable when making a diagnosis of neurodevelopmental disorders, such as ADHD and DCD.

Since DCDQ-C could not reliably reflect motor performance in this group of children, the degree of impairment in daily activities was not adequately assessed to make a definite diagnosis of DCD. A local study of the prevalence of DSM-IV disorders in Chinese adolescents pointed out that 
figures would be overestimated if the impairment criteria were not taken into account. ${ }^{35}$ Although MABC used alone would probably overdiagnose DCD by not considering the impairment factors, it is worth noting that $17.9 \%$ of our study candidates had definite motor problems. This is actually below the 5th percentile of the general population. Thus the magnitude of motor difficulties is substantial and motor problems (with or without a diagnosis of DCD) should not be overlooked in children with ADHD.

\section{Limitations of this study}

There are some limitations to this study. Parents who perceived their children to have motor problems were more keen to participate, leading to a selection bias in the recruitment of children. Although all children were diagnosed with ADHD, they were not a homogeneous group. They were diagnosed by different physicians and were not at a uniform stage of drug treatment. Even though MABC is a widely used tool in Hong Kong, the lack of a local norm might still affect the validity of this study.

\section{Conclusions}

Motor problems in children with ADHD are as common in Hong Kong as in other countries and DCD may have been present in up to $33.7 \%$ of this clinic sample. Acknowledgement of their own strength and weakness will enable patients to better plan future goals. Provision for assessment and management of DCD and other motor problems should be a fundamental part of a comprehensive programme to manage ADHD.

\section{References}

1. Leung PW, Luk SL, Ho TP, Taylor E, Mak FL, Bacon-Shone $\mathrm{J}$. The diagnosis and prevalence of hyperactivity in Chinese schoolboys. Br J Psychiatry 1996;168:486-96.

2. Larson K, Russ SA, Kahn RS, Halfon N. Patterns of comorbidity, functioning, and service use for US children with ADHD, 2007. Pediatrics 2011;127:462-70.

3. Gillberg C, Gillberg IC, Rasmussen P, et al. Co-existing disorders in ADHD-implications for diagnosis and intervention. Eur Child Adolesc Psychiatry 2004;13 Suppl 1:I80-92.

4. Licari $M$, Larkin D. Increased associated movements: Influence of attention deficits and movement difficulties. Hum Mov Sci 2008;27:310-24.

5. Stray LL, Stray T, Iversen S, Ruud A, Ellertsen B, Tønnessen FE. The Motor Function Neurological Assessment (MFNU) as an indicator of motor function problems in boys with ADHD. Behav Brain Funct 2009;5:22.

6. Brossard-Racine M, Majnemer A, Shevell M, Snider L, Bélanger SA. Handwriting capacity in children newly diagnosed with attention deficit hyperactivity disorder. Res Dev Disabil 2011;23:2927-34.

7. Shen IH, Lee TY, Chen CL. Handwriting performance and underlying factors in children with attention deficit hyperactivity disorder. Res Dev Disabil 2012;33:1301-9.

8. Diagnostic and Statistical Manual of Mental Disorders (DSM-5). 5th ed. Washington DC: American Psychiatric Association; 2013.

9. Missiuna C, Cairney J, Pollock N, et al. A staged approach for identifying children with developmental coordination disorder from the population. Res Dev Disabil 2011;32:54959 .

10. Tsiotra GD, Flouris AD, Koutedakis Y, et al. A comparison of developmental coordination disorder prevalence rates in Canadian and Greek children. J Adolesc Health 2006;39:125-7.

11. Kadesjö B, Gillberg C. Developmental coordination disorder in Swedish 7-year-old children. J Am Acad Child Adolesc Psychiatry 1999;38:820-8.

12. Wright HC, Sugden DA. A two-step procedure for the identification for children with developmental coordination disorder in Singapore. Dev Med Child Neurol 1996;38:1099-105.

13. Cairney J, Veldhuizen S, Szatmari P. Motor coordination and emotional-behavioral problems in children. Curr Opin Psychiatry 2010;23:324-9.

14. Losse A, Henderson SE, Elliman D, Hall D, Knight E, Jongmans $\mathrm{M}$. Clumsiness in children-do they grow out of it? A 10-year follow-up study. Dev Med Child Neurol 1991;33:55-68.

15. Sugden DA, editor. Leeds consensus statement: developmental coordination disorder as a specific learning difficulty. In: ESRC Research Seminar Series 2004-2005. Leeds (UK): Economic \& Social Research Council; 2006.

16. Polatajko HJ, Cantin, N. Developmental coordination disorder (dyspraxia): an overview of the state of the art. Semin Pediatr Neurol 2005;12:250-8.

17. Watemberg N, Waiserberg N, Zuk L, Lerman-Sagie T. Developmental coordination disorder in children with attention-deficit-hyperactivity disorder and physical therapy intervention. Dev Med Child Neurol 2007;49:9205.

18. Pitcher TM, Piek JP, Hay DA. Fine and gross motor ability in males with ADHD. Dev Med Child Neurol 2003;45:52535 .

19. Tseng MH, Howe TH, Chuang IC, Hsieh CL. Cooccurrence of problems in activity level, attention, psychosocial adjustment, reading and writing in children with developmental coordination disorder. Int J Rehabil Res 2007;30:327-32.

20. Rasmussen P, Gillberg C. Natural outcome of ADHD with developmental coordination disorder at age 22 years: a controlled, longitudinal, community-based study. J Am Acad Child Adolesc Psychiatry 2000;39:1424-31.

21. Henderson SE, Sugden DA. Movement assessment battery for children. London: Psychological Corporation; 1992.

22. Croce RV, Horvat M, MaCarthy E. Reliability and concurrent validity of the movement assessment battery for children. Percept Mot Skills 2001;93:275-80.

23. Chow SM, Henderson SE. Interrater and test-retest reliability of the Movement Assessment Battery for Chinese preschool children. Am J Occup Ther 2003;57:574-7.

24. Wilson BN, Kaplan BJ, Crawford SG, Campbell A, Deway D. Reliability and validity of a parent questionnaire on childhood motor skills. Am J Occup Ther 2000;54:484-93.

25. Schoemaker MM, Flapper B, Verheij NP, Wilson BN, Reinders-Messelink HA, de Kloet A. Evaluation of the 
Developmental Coordination Disorder Questionnaire as a screening instrument. Dev Med Child Neurol 2006;48:66873.

26. Tseng $\mathrm{MH}, \mathrm{Fu} \mathrm{CP}$, Wilson BN, Hu FC. Psychometric properties of a Chinese version of the Developmental Coordination Disorder Questionnaire in communitybased children. Res Dev Disabil 2010;31:33-45.

27. Macfarlane D. Children's physical activity patterns and the implications for health. In: Johns DP, Lindner KJ, editors. Physical activity and health of Hong Kong youth. Hong Kong: The Chinese University Press; 2006: 67-87.

28. Shimoni M, Engel-Yeger B, Tirosh E. Participation in leisure activities among boys with attention deficit hyperactivity disorder. Res Dev Disabil 2010;31:1234-9.

29. Goyen TA, Lui K. Developmental coordination disorder in "apparently normal" schoolchildren born extremely preterm. Arch Dis Child 2009;94:298-302.

30. Edwards J, Berube M, Erlandson K, et al. Developmental coordination disorder in school-aged children born very preterm and/or at very low birth weight: a systematic review. J Dev Behav Pediatr 2011;32:678-87.

31. Leung TN, Roach VJ, Lau TK. Incidence of preterm delivery in Hong Kong Chinese. Aust NZ J Obstet Gynaecol 1998;38:138-41.

32. Bart O, Podoly T, Bar-Haim Y. A preliminary study on the effect of methylphenidate on motor performance in children with comorbid DCD and ADHD. Res Dev Disabil 2010;31:1443-7.

33. Flapper BC, Schoemaker MM. Effects of methylphenidate on quality of life in children with both developmental coordination disorder and ADHD. Dev Med Child Neurol 2008;50:294-9.

34. Stray LL, Stray T, Iversen S, Ruud A, Ellertsen B. Methylphenidate improves motor functions in children diagnosed with hyperkinetic disorder. Behav Brain Funct 2009;5:21.

35. Leung PW, Hung SF, Ho TP, et al. Prevalence of DSM-IV disorders in Chinese adolescents and the effects of an impairment criterion: a pilot community study in Hong Kong. Eur Child Adoles Psychiatry 2008;17:452-61. 